\title{
TITLE - Hydroponics and community gardens: insights on the interaction between urban farmers and technology.
}

Authors:

\author{
Silvio Caputo - School of Architecture, University of Portsmouth -silvio.caputo@port.ac.uk \\ Heather Rumble - Department of Geography, University of Portsmouth - heather.rumble@port.ac.uk \\ Martin Schaefer - Department of Geography, University of Portsmouth-martin.scahefer@port.ac.uk
}

\begin{abstract}
Large-scale hydroponic systems, a highly resource and space efficient form of cultivation, already contribute substantially to global food production. Recognising the value of such an efficiency, a few hydroponic/aquaponics community projects and small social enterprises have recently been implemented in Europe. In addition to food production in itself, hydroponic gardening can be an opportunity in terms of not only enabling urban communities to produce their own food in absence of land suitable for cultivation, but also in re-skilling in a range of fields, from plumbing and energy resource management, to computer programing. The advantages of simplified hydroponics in a densely built urban context has been investigated before in the developing countries (see Facondini et al 2010) and in the developed world (Laidlaw and Magee, 2016). We intend to build on the latter and generate further insights on the possible barriers to the uptake of soil-less, small-scale, digitally operated hydroponic systems from community of gardeners and people involved in gardening projects. Gardening is traditionally an on-soil activity, with associated benefits such as physical exercise and interaction with nature. We aim to understand whether a different, technology-based approach to food cultivation can be perceived as a limit from these communities. In collaboration with the community association Big Local Fratton, we are in the process of installing a digitally-operated hydroponic unit in a community garden located in a primary school, in Portsmouth, and ask gardeners to manage it. Interviews will be held between July and September with students and parents, volunteers of the community garden, and a wider community of gardeners connected with Big Local Fratton. This paper will present the initial analysis of the interviews.
\end{abstract}

\section{Introduction.}

The growing interest in Urban Agriculture (UA) in Europe and beyond results in an increased need for urban land that can be suitable for cultivation. Some cities are allocating land for this purpose in order to meet demand for allotments and community gardens Taylor and Lovell, 2013), but urban land can be scarce and. Moreover, soil in cities can be contaminated (Bugdalski, 2013; Sipter, 2008) and some gardening habits can worsen the condition of the soil (e.g. the use of chemical fertilisers, pest control, timber treatment, etc.) (Voigt and Leitão, 2016). Consequently, many UA projects resort to space-efficient and safe approaches to grow edible plants by occupying unused or neglected areas such as rooftops or paved surfaces, and by using raised beds filled with safe soil enriched with compost. One of the most space-efficient approaches to growing food is hydroponic systems, which are now a consolidated form of crop production worldwide.

Hydroponic systems have been designed as a space efficient, resource efficient form of agricultural production (Curtis et al., 2015) and, at present, they represent a considerable source of industrially grown produce (www.transparencymarketresearch.com/hydroponics-market.html; Jensen, 1999). They require sophisticated technology, specialist skills and expensive equipment. Simplified forms of hydroponics, however, can be implemented by non-specialists, sometimes with ingenious results. Indeed, it is sufficient to browse the web to come across some quite sophisticated DIY projects, some of them including digitally operated components (see for example http://www.bltrobotics.com/farm.php). Some community groups, social enterprises and small for-profit enterprises, have already embraced hydroponic and aquaponic technologies as a form of sustainable production (Laidlaw and Magee, 2016). Indeed, hydroponic systems are a promising opportunity to grow food in dense cities and utilise urban resources that are still largely untapped, such as rainwater and solar energy. But the advantage that technology offers can also be a hindrance. One of the benefits of UA as perceived by urban farmers is the possibility to connect with nature (Travaline and Hunold, 2010) in an urban context that is progressively detached from natural cycles. Barthel et al. (2010) suggest that allotments are the place where ecological memory (i.e. a knowledge of the natural world gained through the practice of managing the land for agricultural purposes) is preserved. In this perspective, would urban gardeners embrace a technology like hydroponics, which could be envisaged as an artificial, unnatural way to produce food? 
Similarly, would gardeners accept technology as a means to grow food sustainably when too often this is associated with industrial, unsustainable methods of agricultural production?

In order to answer to these questions, we have built and installed hydroponic equipment in two community gardens in Portsmouth in order to better understand the reception of urban farmers to an alternative, technology-based, soil-less form of food production. The paper presents the initial results of the project, which will end in October, with a final round of interviews to be held during a citywide community gardens event. The paper will firstly briefly review literature on community projects with hydroponics. It will subsequently present the methodology for this project before focussing on the results and the ensuing discussion.

\section{Hydroponic systems of cultivation.}

The global market of hydroponically grown produce is big and in expansion. Estimates suggest that, in 2016, it accounts approximately for US\$ 6,934.6 m (http://www.transparencymarketresearch.com/hydroponicsmarket.html). Between 20,000 and 25,000 hectares of land are currently under hydroponic development globally (http://web.mit.edu/12.000/www/m2015/2015/hydro_agriculture.html). The uptake of this cultivation system is bolstered by concerns about soil quality, and the evidence that greenhouses have higher yields than traditional cultivation. In 2008, the largest hydroponic greenhouse in the UK, Thanet Earth, started its construction on the Isle of Thanet, Kent. It covers 90 hectares of land and it produces mainly tomatoes, peppers and lettuce (www.thanetearth.com). Thanet Earth uses highly sophisticated systems of indoor environmental control, but it is possible to use hydroponic systems in a simplified way. There are a number if publications (Orsini et al., 2013; Fecondini et al., 2010; Tabares, 2003), documenting how simplified hydroponic systems have been utilised in developing countries to enable a higher degree of food security within low-income communities. Simplified hydroponic systems are based on the principle that plants can be grown not on soil but in other substrates (such as coconut fibre) or simply in water as a growing medium. Although simplified, such systems still require training and the knowledge necessary to maintain and manage basic equipment such as a pump. In this perspective, some organise training courses in low income communities in Latin America, analysing the barriers that may arise in the management of the hydroponic systems installed. Some of these barriers related to food at large. Mezzetti et al. (2010) found that only a limited number of people interviewed in a food market were aware of the threats of contamination from heavy metals in the food purchased in the market. This suggests that the majority of customers may not fully grasp the advantages that hydroponics systems - in terms of healthy food can bring in situations in which - for example, the soil is not suitable for cultivation, which is one of key advantages from hydroponic systems.

Limited literature is available that focuses on urban, small-scale hydroponic enterprises in the global north and the barriers to their economic viability (see for example Laidlaw and Magee, 2016). There are also a few studies on hydroponic systems in developing countries such as India (Sardare, 2013) and and even Martinica (Tixier and DeBon, 2006). However, to date, much less attention has been given from researchers to community-based hydroponic projects. This is perhaps because at present, to the knowledge of the authors, only a small number of such projects have been implemented across Europe (see for example Bristol Fish Project, www.bristolfish.org/ for aquaponics and Hemmaodlat in Malmo - www. hemmaodlat.se - for hydroponics). Hemmaodlat, in particular, is a project that is relevant to this study. It was started as an organisation located in a neighbourhood of Malmo predominantly occupied by low-income groups and immigrants. The area is densely built and no green space for cultivation is available locally. Moreover, the Swedish summer is short and not always ideal to grow crops. Against this backdrop, the aim of the organisation is to promote hydroponic systems amongst people as a way to grow edible plants possibly at home, using low-cost equipment, has now more than 70 members although none of these are part of the local community the project was set up to attract. In fact, to date, the organisation has been very successful in attracting the attention of people - mainly educated - who are keenly interested in investigating alternative methods of food production in cities but largely unsuccessful in raising awareness of the potential of hydroponic systems within their target group (Niclas Mörck, personal communication).

Reasons for the apparent slow uptake of hydroponic and/or aquaponic systems in the context of fast-growing interest in UA practices in the global north can be many. These include lack of information regarding the advantages that hydroponic systems can yield, and the time and effort necessary to implement low cost, DIY 
systems, while learning skills necessary to run them. Furthermore, UA is a multifunctional practice (Koopmans et al., 2017), with farmers appreciating it also for the opportunity to be in contact with a 'natural environment' while undertaking a practice that can mitigate urban environmental degradation (see for example loannou et al., 2016). Such an aim can be associated with gardening on soil but much less with hydroponic systems. With this in mind, the project here documented aims to test these assumptions by interviewing potential users of simplified hydroponic systems.

\section{Methodology.}

The current project develops over three phases: firstly, the identification of suitable organisations that can host the hydroponic frame; secondly, an investigation of DIY types of hydroponic systems, which can be demonstrated to participants in the project that such systems can be easily and affordably implemented; and thirdly, the interviews of a selected group of people using the system.

Initial contacts with two community gardens in Portsmouth were made to assess their availability to participate in the experiment. Portsmouth is a city of approximately 200,000 inhabitants, with the second highest density of inhabitants per $\mathrm{m}^{2}$ in the UK. Allotments sites are available, but space for expansion is understandably limited in such a dense city. To date, 15 community gardens are run over the entire city. In particular, Fratton Big Local (an organisation founded to strengthen the community life of the Fratton neighbourhood, one of the areas with highest deprivation levels in Portsmouth (DCLG, 2015)), started one on the grounds of an infant school. This community garden (CG1) is composed of a poly-tunnel and a patch of land with 5 small allotments (approximately $5 \mathrm{~m}^{2}$ each), allocated to local families. The programme of this community garden includes activities with children to inform them about horticulture and healthy food. Local volunteers are involved in the day-to-day running and managing of the garden. The second community garden, Southsea Greenhouse (CG2) is a small patch of land within the Commons, a green area that orders the southern waterfront of the city. This garden is within one of the least deprived wards in Portsmouth. Similar to the other community garden, plots are rented to individuals and families, and number of varied initiatives such as stalls at local community events ensure the involvement of quite a large and varied group of people in the community garden's activities. A core group of gardeners ensures continuity to the managing of the community garden.

Based on research of available hydroponic systems, two different systems were chosen for installation. The first was a vertical frame (VF), installed at CG1. This frame is a DIY hydroponic system, based loosely on the Robotic Urban Farm System developed by BLT Robotics (http://www.instructables.com/id/VerticalHydroponic-Farm/), which utilises standard components for plumbing (i.e. PVC pipes and joints). The frame is operated via a digital component (Arduino), programmed by the authors. The digital component sends alarms to the farmers via email in the event of pump failure and has the potential to be programmed to supply information such as $\mathrm{pH}$, temperature, etc. (though these features have not been used in this project). The team built the frame to test the feasibility of construction for non-experts and to eventually brief volunteers who would be interested in building frames for private use. The second hydroponic system was a ready-made ebb and flood table (EFT), installed at CG2 and fitted with the same robotic technology as VF. The two hydroponic systems were installed within the community gardens, both with modifications made to allow them to run from solar panels. These installations allowed the project team to interview those who show interest in the hydroponic systems. The diversity of groups involved in each community garden project (i.e. schoolchildren, their families, households renting plots, volunteers, groups involved in collateral activities, etc.) enabled the gathering of data from people with different backgrounds. These included urban farmers (i.e. core groups running the community gardens), volunteers (i.e. people involved regularly in gardening) and general participants (i.e. people occasionally involved in gardening or visiting the gardens).

Participants' opinions are gathered over three events. The first one is the school fair of the infant school (CG 1) in July, 2017. On this occasion, the VF system is shown as part of the outreach activities of the community garden and visitors are interviewed. The second one is the community garden open day, which will be held in October, 2017 (CG1 and 2). On this occasion, visitors are likely to be mainly volunteers involved in community gardens and visitors with an interest in food gardening. The third series of data will be collected continuously from installation until the end of the growing season (around the end of October, 2017). In these sessions, 
those gardeners that have been using the systems regularly will be interviewed. Interviews are semistructured, with a short questionnaire (see Appendix 1) aimed at determining the prior knowledge of hydroponics held by the interviewee, the positive or negative perception when compared to conventional onsoil horticulture practice and produce, and the willingness to engage with this cultivation system, in addition to any personal advantages or barriers they have perceived while using the system. The current paper presents and discusses interviews held in the course of the first event, where 24 participants were interviewed. At the interviewers' discretion, not all questions were asked to every participant. Demographic information was not explicitly collected; due to the nature of the event, most of the participants were local (i.e. from Fratton), though a few were from nearby localities, such as Southsea or Hayling Island. Ages were diverse, ranging from approximately 5 to 70 and most participants had some connection to the school (i.e. family connections). Opinions gathered were annotated, analysed through text analysis and quantitatively grouped to identify predominant trends. Results of quantitative and qualitative analysis are presented in the following section. It is not the aim of this paper to draw firm conclusions from such a small sample of interviews, rather to identify recurrent themes and unique observations that can direct future study in this area.

\section{Results.}

Results from the interviews are grouped under headings capturing the main concerns or foci identified when analysing data gathered.

Prior knowledge of hydroponic systems - Over half (fourteen) of the respondents stated that they did not know that food could be grown without soil, whilst ten stated that they had known this previously. Eight participants were familiar with hydroponic systems, whilst thirteen had never heard of them. Two participants were not sure if they had previously heard of hydroponics. Three of the participants had some prior experience with hydroponic systems: Two had friends or family working in the hydroponic industry, whilst one participant had tried to build a system in their kitchen, though had been unsuccessful. In general, it seemed that those participants that gardened at home were more likely to have heard of hydroponics before. Overall, only six of the participants were aware that many supermarket sold fruits and vegetables are grown hydroponically.

Chemicals - Only three respondents stated that they would not eat food that had knowingly been grown in hydroponic systems, and all three of these participants had not been aware of hydroponics before the day of data collection. However, many of those that were not put off by hydroponically grown vegetables seemed to associate hydroponic with chemical use. Only one participant stated that food grown in rural environments would also likely have chemical input. Two participants had positive associations about hydroponics and the use of chemicals. One participant suggested that hydroponic farming is "cleaner" than other types of farming, whilst another was an enthusiastic organic gardener and stated that they had considered using hydroponics before to aid in pest control.

"Normality" - Several participants suggested that hydroponics were not normal. Several participants stated that they would rather eat "normal" food and some suggested that they would rather eat something grown naturally.

Time, space and money - Of the nineteen people asked whether they would consider keeping a hydroponic system at home, eleven people said they would consider it, whilst four were unsure and four would not. Having heard of hydroponics before was not necessarily a prerequisite to being willing to have one at home; Of the thirteen people who had not previously heard of hydroponics, six would still consider owning one, three would not, one was not sure and two were not asked this question. None of the participants who had heard of hydroponics before stated that they would not have a system at home. Ironically, the most common reason given by participants for not adopting a system like this was space. However, most participants thought a hydroponic system would be a good space saver and this was commonly stated as a reason to have one. Time saving and affordability were also given as reasons for adopting this kind of system.

Conventional gardening - Thirteen of the respondents said that they participate in gardening at home. Most did not specify what they grew at home, but of the three that did all gardened for vegetables, whilst two of these also grew flowers. Eight did not garden. 
Technology and botany - Only one participant was more interested in the technological aspect of the hydroponic frame more than the plants themselves and this participant asked many questions about the Arduino. No participants showed any interest in the types of plants grown in the frame, though one participant did mention that the plants looked healthy and several asked what kinds of foods could be grown in it. In general though, people were not interested in details but the overall concept of the hydroponic system.

\section{Discussion.}

The results section highlights patterns and themes recurring in the interviews, thus giving a glimpse of the attitude that people who are generally not growing crops in cities may take on hydroponics. This section will further elaborate on some of these themes.

Although the majority of the interviewees were not aware of hydroponic systems and the likelihood that some of the crops (e.g. tomatoes) they purchase from the big retailers in the UK are likely to be grown hydroponically (Caspall et al., 2006 they were nevertheless reasonably well informed about the threats of industrial food production such as chemical fertilisers. Debate on food in media, in the UK and beyond, is very active (Blue, 2010), possibly also because of threats to the health of consumers that have shaken their confidence in industrial food supply and production. Food threats coming from animals reared and fed in such a way that increases health risks, for example, are becoming common (Knowles et al., 2007), hence leading to a higher level of information on the food industry practices and issues related to food generally. Nevertheless, at least in the sample of people interviewed, there are still difficulties in making informed choices about food. A case in point is that many of those that were not put off by hydroponically grown vegetables seemed to associate hydroponics with chemical use and mentioned this as a qualifying statement, for example stating, "I would eat the food from this if no chemicals are used". This suggests that, while there is awareness of chemicals as one of the components of food production, there is more diffidence of food grown with chemicals that can be dispensed under the control of the consumer/grower than those that are used at an industrial scale.

Another interesting concept surfacing from the interviews is the idea of artificial as opposed to natural. Unexpectedly, none of the participants that already gardened seemed put off by the "artificial" nature of the hydroponic system. In fact, this group were most interested in trying it themselves and this was most often stated as being about fun or interest. One participant said, "I like growing food and would have no problem having a hydro system at home", whilst another said they, "...garden for fun and for being outdoors. But this also seems interesting." One participant, who described himself as a "down on the soil gardener" said that he "... would be interested to know if this is an enjoyable way of gardening." Despite this curiosity towards an alternative method of gardening from some of the interviewees, others showed strong adverse opinions, with one of them using the term 'alien' ("I can't decide [whether] I would eat it [hydroponically grown food] or not, as it's so alien to me."). This suggests that the issue of normality and the definition of natural is a polarising topic. There seemed to be no association of natural produce with food that is grown on soil and that follows the patterns of life of the natural realm. However, there is some diffidence towards soil-less methods of cultivation when it comes to flavour. Some of our participants mentioned that taste was important to them, suggesting that hydroponic foods would only be acceptable if they tasted the same as "normal" foods. In addition, taste was given as a reason to garden more generally, "Things taste better when grown yourself." Taste, however, was not as big a factor for discussion as chemical use and space.

As mentioned above, a rational use of space is one of the biggest advantages that hydroponic systems can provide. This is true not only when considered at an industrial scale but also in terms of urban agriculture. There is awareness of such an advantage but at the same time there seems to be limited understanding of what this entails for personal production and consumption. For most participants, this was a personal observation, "This is perfect for a busy person. Someone in house used to garden but now I have no time." One participant stated that this kind of growing is good in compact cities, "It makes sense to grow hydroponically in cities, where there is little space." Yet, as mentioned in the section above, many could not think of any space where a hydroponic frame or small cabinet could be located within their homes. Again, it can be surmised that the advantage in terms of food safety that hydroponic systems can provide, is not fully perceived and that perhaps this should be more effectively communicated when explaining the advantages of 
this system. In apparent contradiction, those participants that said they would be put off eating food grown hydroponically, still stated that they would be happy to try their own system at home. Whilst this could demonstrate open mindedness, it is worth considering that asking hypothetical questions is not always an accurate measure of true intent (Cummings et al., 1995).

\section{Conclusions.}

The initial results of this project, which looks at the receptiveness of urban gardeners and non-gardeners to simplified hydroponics, identify some factors of hindrance to their diffusion. Generally, interviewees show a good understanding of food production and threats associated to it. Yet, when it comes to choice, there seem to be an unjustified higher reliance on traditional methods as far as the use of chemicals is concerned. Another point requiring attention is the definition of 'natural'. In the opinion of the interviewees, this concept seems to be associated with food produced industrially rather than grown hydroponically. But can the former really be understood as natural, given that the environment for cultivation is heavily manipulated by man? Perhaps, the most misunderstood factor is space and the opportunity that hydroponics offer in this area, especially in an urban environment. These findings all point to a lack of in-depth information and debate. It is expected that interviews of other groups of people visiting or using the hydroponic equipment will add more depth to this study.

\section{References.}

Barthel, S., Folke, C. and Colding, J. (2010) Social-ecological memory in urban gardens-Retaining the capacity for management of ecosystem services. Global Environmental Change 20, pp. 255-265

Blue, G. (2010) Food, publics, science. Public Understanding of Science 19(2), pp. 147-154.

Bugdalski, I. L., Lemke, L. D. and McElmurry, S. P. (2013) Spatial variation of soil lead in an urban community garden: implications for risk-based sampling. Risk Analysis

Caspall, N., Drakes, D. and O’Neill, T. (2006) Pesticide Residue Minimisation: Crop Guide - Tomatoes. Food Standard Agency.

Cummings, R., Harrison, G., \& Rutström, E. (1995). Homegrown Values and Hypothetical Surveys: Is the Dichotomous Choice Approach Incentive-Compatible? The American Economic Review, 85(1), 260266.

Curtis, J., Costa, B., Kennard, N., Landau, J., Smith, J. and Teng, J. (2015) Urban Farming: Bringing Hydroponics to Georgia Tech. Green Innovation 2015. Downloadable at http://www.esw.gtorg.gatech.edu/wpcontent/uploads/Written-Report.pdf

Department for Community and Local Governments (2015) The English Indices of Deprivation 2015, Research report. London: DCLG

Fecondini, M., Damasio de Faria, A. C., Michelon, N., Mezzetti1, M., Orsini, F. and Gianquinto, G. (2010) Learning the Value of Gardening: Results from an Experience of Community Based Simplified Hydroponics in North-East Brazil. Acta Horticulturae 881, pp. 111-116.

Ioannou, B., Morán, N. and Sondermann, M. (2016) Grassroots Movements - Towards Cooperatove Forms of Green Urban Development? in Bell, S, Fox-Kaemper, R, Benson, M. Caputo, S, Kaeshavarz, N, Noori, S. and Voigt, A. (eds) (2016) European Urban Allotments. Routledge.

Jensen, M. H. (1999) Hydroponics Worldwide. Acta Horticolturae 481, pp. 719-730.

Knowles, T., Moody, R. and McEachern, M. G. (2007) European food scares and their impact on EU food policy. British Food Journal 109 (1), pp. 43-67.

Koopmans, M. E., Mettepenningen, E., Kunda, I., Keech, D. and Tisenkopfs, T. (2017) Creating Spatial Synergies around Food in Cities. Urban Agriculture and Regional Food Systems 2, pp. 1-9.

Laidlaw, J. and Magee, L. (2016) Towards urban food sovereignty: the trials and tribulations of communitybased aquaponics enterprises in Milwaukee and Melbourne, Local Environment, 21(5), pp. 573-590.

Orsini, F., Fecondini1, M., Michelon, N. and Gianquinto, G. (2010) Women and Simplified Hydroponics: Community Gardening as a Way of Emancipation in Trujillo, Peru. Acta Horticulturae 881, pp. 169172.

Orsini, F., Kahane, R., Nono-Womdim, R. and Gianquinto, G. (2013) Urban agriculture in the developing world: a review. Agronomy for Sustainable Development 33(4), pp 695-720. 
Sardare M. D. and Admane S. A. (2013) A review on plant without soil - hydroponics. IJRET 2(3), pp. $299-304$.

Sipter. E., Rózsa, E., Gruiz, K., Tàtrai, E. and Morvai, V. (2008) Site-specific risk assessment in contaminated vegetable gardens. Chemosphere 71, pp. 1301-1307

Tabares, C. M. (2003) Hydroponics in Latin America. Urban Agriculture Magazine ,p 8. RUAF

Taylor, J. R. and Lovell, S. T. (2013) Urban home food gardens in the Global North: research traditions and future directions. Agriculture and Human Values 31(2), pp. 285-305.

Tixier, P. and Hubert De Bon, H. (2006) Urban horticulture in Cities farming for the future: Urban agriculture for green and productive cities. Ottawa: ETC-UA/RUAF, IDRC.

Travaline, K. and Hunold, C. (2010) Urban agriculture and ecological citizenship in Philadelphia. Local Environment 15(6), pp. 581-590.

Voigt, A. and Leitão, T. (2016) Lessons Learned: Indicators and good practice for an environmentally-friendly urban garden in in Bell, S, Fox-Kaemper, R, Benson, M. Caputo, S, Kaeshavarz, N, Noori, S. and Voigt, A. (eds) (2016) European Urban Allotments. Routledge.

1. Do you know that you can grow planta without soil?

2. Do you know what hydroponic systems are?

3. Do you know that some of the vegetables you eat are grown with hydroponic systems?

4. Now that you know, would you change your choice of food when you shop in the supermarkets?

5. Do you practice gardening and grow flowers or edible plants?

6. Do you think it is good to grow food in cities?

7. Would you keep a hydroponic frame at home? 